\title{
Comparison of the Learning Abilities of Chinese and American College Students and Cultivative Approaches
}

\author{
Guang Shao \\ Dalian Maritime University \\ Dalian, P.R. China
}

\author{
Qiang Shao \\ Dalian Maritime University \\ Dalian, P.R. China \\ Zhihao Su \\ Dalian Maritime University \\ Dalian, P.R. China
}

\author{
Kaiming Sun \\ Dalian Maritime University \\ Dalian, P.R. China \\ Yanfeng Wang \\ Dalian Maritime University \\ Dalian, P.R. China
}

\begin{abstract}
By means of the comparative analysis of the learning abilities of Chinese and American college students, it has been found out that Chinese and American college students have differences in learning motivation and purpose, mainly because of the two countries' difference in national system, ideology and values, leading to the differences in Chinese and American education ideas, student-affairs managements, classroom teachings and examinations. China should cultivate college students' learning ability by adopting such measures as guiding self-planning to improve their learning goals, adjusting the learning method to improve their learning ability, enhancing the self-motivation with the help of recessive education, carrying out the management system and encouraging the students to participate in the learning practice.
\end{abstract}

Keywords-Chinese and American college students; learning abilities; learning motivation; learning purpose

\section{INTRODUCTION}

The rapid development of higher education has brought new challenges to the training of talents in colleges and universities. New requirements have been put forward for the innovation and entrepreneurship education, scientific and technological innovation and the learning ability of college students. Living and growing in social transformation, the college students after $95 \mathrm{~s}$ bear the pressure of making a living and getting jobs in the tide of the market. We should cultivate college students' comprehensive learning ability to promote their all-round development in the new circumstances. Based on the theory of constructivism, this paper explores ways to cultivate and enhance the learning ability of college students in China by comparing the learning situation of Chinese and American college students and using the mature academic guidance system of the United States as a reference.

\section{THE CONNOTATION AND FUNCTION OF CONSTRUCTIVIST LEARNING THEORY}

\section{A. The Essential Characteristics of Constructivist Learning Theory}

Constructivism derives from the theory of children's cognitive development. Constructivist Learning Theory emphasizes the constructive of knowledge learning and the initiative of cognitive subjects. Since 1990s, Constructivist Learning Theory has been paid more and more attention from all over the world. It has become a mainstream theory of educational reform and plays a positive guiding role in the reform of higher education teaching. This theory holds that learning is the process of giving full play to the initiative of the students to construct meaning under the external environment conditions, in which the problem solving is the core of learning, thinking and developing.

\section{B. The Function of Constructivist Learning Theory}

The important role of Constructivist Learning Theory is mainly reflected in the influence on the cultivation of students' learning ability, namely the influence of learning autonomy and the social attributes of learning. In terms of the influence of learner autonomy, Constructivist Learning Theory advocates the idea of student-centered education, which holds that learning is the process of the students' active construction of knowledge. This requires that learners have high learning initiative and independent thinking ability. Taking the students as the main body and center of education, this idea can stimulate the students' ability to study 
independently, adjust and improve the existing knowledge constantly, build new knowledge, cultivate comprehensive ability, and strive to become innovative talents with the spirit of exploration and lifelong learning. In terms of the social attributes of learning, social attributes can be classified into three aspects: participation experience, creation of learning situations and help from others. The self-study of college students does not separate from the society influence and the help from others. They do not carry out the study alone, but grasp the ability of self-study as soon as possible by the scientific application of learning social attributes.

\section{COMPARISON OF LEARNING ABILITY BETWEEN CHINESE AND AMERICAN COLLEGE STUDENTS}

\section{A. The Difference of Learning Motivation}

1) Enrollment management system restricts college students' learning ability: The enrollment system of American universities is quite different from ours. Colleges and universities in the United States generally adopt the registration system and the trial reading system. College students can choose schools, majors and courses according to their interests. Their study is mainly based on self-study and discussion learning so the initiative of college students in America is much stronger. Domestic colleges and universities are basically fixed credit system, unified enrollment, unified teaching plan and unified curriculum. It is difficult to teach students in accordance with their aptitude and develop their specialty so that Chinese college students' learning enthusiasm is not high.

2) High tuition fees become effective driving force for college students' active learning: Tuition fees in American colleges and universities are generally higher and colleges and universities have the power to adjust their tuition independently so the tuition fees occupy a very high ratio in the household expenditure. College students are accustomed to earning money while reading, which makes American students have higher learning motivation. In contrast, the majority of college students' tuition fees are paid by their parents and the tuition fees of students with financial difficulty can be solved through various channels. There are not many college students who actually pay their tuition through part-time-work and part-time-study. In many universities in China, especially in local universities, a large number of college students do not cherish the existing learning opportunities.

\section{B. The Difference of Learning Purpose}

The purpose of learning is mainly divided into the learning purpose pointing to oneself, the learning purpose pointing to the society and the learning purpose pointing to others. The learning purpose pointing to one refers to the learning purpose to meet the needs of self-development. The students who have learning purpose pointing to them can evaluate them correctly, set the way of self-development, and take active and effective measures to achieve the purpose of learning. The learning purpose pointing to the society is based on the social needs, and the learning plan is adjusted according to the changes in the social and economic situation. The learning purpose pointing to others is based on the expectations of others. Some students study in order to repay the kindness of their parents, some for the sake of not losing to others, and some for not living up the teachers' expectations. The purpose of most American university students belong to the learning purpose pointing to oneself, which accord with American social culture and personal values. The purpose of college students in China is mostly the learning purpose pointing to others, which is related to the small production mode of feudal society in the past several thousand years. The difference of learning purpose directly influences the learning attitude, learning interest, learning habit, learning method, learning efficiency and learning result.

\section{Reasons for the Differences in Learning Ability Between Chinese and American Students}

1) Differences in learning ability due to different learning motivation: Students in American university take interest as the main driving force, and universities fully respect the cultivation of College Students' innovative ability. Many universities regard "scientific research methods" as a compulsory course for junior college students. For example, the famous Massachusetts Institute of Technology in the United States advocates that college students should "learn while studying and study while learning". The learning motivations of college students in China is mainly as follows: "change the family status" type, "gratitude" type, "fame and wealth" type, "sensible and contributive " type, all aiming to maintain and change their own survival status.

2) Differences in training objectives due to different national systems:Twenty-first century is the century of knowledge innovation. The rapid development of science and technology is always accompanied by changes of people's thinking way. The training objectives of American colleges and universities have transited from the initial emphasis on moral education to the emphasis on intellectual education, and finally to the comprehensive development of talents. The cultivation of university students in China has also been transformed from the initial emphasis on intellectual education to the comprehensive training of knowledge and ability. China and the United States have different political systems, ideological systems and values so the training objectives are also different.

3) Differences in educational models due to different learning conditions.

a) The different ideas of the educational model between China and the United States: In the United States, there are no clear concepts such as "moral education", "Ideological and moral education", "Ideological and political education" and so on. The "civic education" in American colleges and universities is the ideological and political education in our country. The goal of American 
moral education is to train students to pay attention to the development of the personality of college students rather than the awe of God and now it transforms to cultivate the "qualified citizens" of the country which emphasizes the cultivation of "national spirit". Moral education actually covers four aspects: civic education, personality education, values education and religious education. The moral education in colleges and universities of China is mainly confined to the campus and the classroom. Since the new century, the moral education in colleges and universities of China has been extended to the outside of the school, but the close contact with the social reality is not enough, the content is relatively simple, and the improvement of the ability of college students is insufficient.

b) Different management of college students in China and the United States: The rapid development of college and university affairs in the United States is benefited from the continuous development of American social economy and culture, followed by the operation discipline of "student affairs" itself. College students are always the primary duty of the development of "student affairs"; the core task of "student affairs" is to pay attention to the "student development"; and the development of student affairs personnel provides personnel security for "student affairs"; the management model of "participation" and "cooperation" is a powerful guarantee for improving the management level of "student affairs". At present, the specialization of counselors in our country is advancing progressively. It is clear that counselors have dual roles, cadres and teachers, and also have dual functions, leadership and management in their work. Now the selection of counselors does not require professional origin, but emphasize the professional guidance of college students' adaptation problems, mental health problems and learning problems during the school period, however it cannot meet the standards of foreign specialization.

c) Different classroom teaching and course examination process in China and the United States: American students' observation, creativity and imagination are superior to those of domestic university students, especially in terms of imagination. College Teachers in the United States focus on taking effective measures to prompt college students to take the initiative in teaching activities. They seldom instill knowledge but leave more time to make college students think and ask questions actively in order to fully cultivate their ability to think and acquire knowledge initiatively. Domestic colleges and universities always lack of studying the college students' interest furtherly. And the platforms for the effective mobilization of students' interest in learning and energetic learning process are also insufficient so that the students graduate in domestic colleges and universities are nearly the same. In terms of curriculum examination, American universities emphasize process management, focus on interview rather than written examination, pay attention to the application of comprehensive knowledge and emphasize professional practice ability. However, domestic universities attach importance to written examination, which weakens the cultivation of college students' practical ability and ignores the practical knowledge and experimental skills of college students.

\section{The Ways of Cultivating Students' Learning Ability in China}

1) To guide self-planning and improve learning goals: Through self-awareness, college students have established the some proper goals and career ideals. The main task of university students' self-planning is to plan according to their objectives, and stages clearly trying to take fewer detours. Experiential teaching in constructivist learning theory advocates the participation of college students to understand the meaning of knowledge. For college students who lack of social experience, they need help from others in some critical periods or when they encounter difficulties. The professional consulting projects, such as admission guidance, academic consultation, psychological counseling and employment guidance, have come into being throughout the whole college life to solve all kinds of problems. American colleges and universities have special personnel to guide professional counseling and psychological counseling, such as the University of California at Los Angeles with more than 50 professional psychologists, 8 to 12 psychiatric doctors and 24 psychologists. Most staff have a PhD in psychology, and serve 14000 college students annually. In our country, more and more colleges and universities begin to pay attention to the professional construction of the college students' working team, the improvement of the level and professional ability of this team. They carry out the training courses for the professional instructors and psychological trainers to improve the professional quality of the counselors to guide the college students' employment skills and career development and guide them to make reasonable selfplanning and enhance learning objectives.

2) To adjust the learning methods and improve the learning ability: The inquiry teaching based on constructivist learning theory lays stress on the cultivation of College Students' self-learning ability and innovative ability. To cultivate self-learning ability, teachers need to offer the possible support and high expectations within the scope of learning to help college students build confidence in learning. In the process of self-study, we should avoid experiential and command learning, and adopt a heuristic and interactive way of learning to encourage university students to develop critical thinking. In and out of class, teachers should not only impart knowledge to college students, but also pay attention to the way of thinking of these knowledge creators. They should teach college students to use dynamic, systematic and open views to see the problems and master the methods of solving problems, guide the students to choose by themselves, explore independently and learn freely. The leadership of colleges 
and universities should form a consensus; the relevant functional departments should introduce effective policy incentives to encourage innovation; all teachers should take different teaching methods consciously and creatively according to college students' conditions and course conditions. Only in this way, the reform can be put into practice. o At the same time, we should increase academic guidance for college students. Academic guidance is one of the ways to create a good learning atmosphere and cultivate college students' self-learning ability. For example, the Supplement Instruction program is being promoted globally. The project is an extra-curricular tutorial that is driven and organized by college students. The core of the project is to discuss with each other through 2 to 3 sessions per week, where students can communicate on learning skills and learning strategies and help themselves to familiarize with knowledge. At present, some colleges and universities have carried out the project of Mentoring Programme and mutual-help group, similar ways of sharing the learning method by the peers so that the college students can improve their self-learning ability in the process of discussion and practice.

3) To promote self-motivation with the help of implicit education: Comparing with explicit education, implicit education refers to the educational process that is unconsciously influenced by the implicit, unplanned, indirect and implicit social activities under the macro dominance. It influences the educator's thoughts, attitudes and emotions by means of "subtle changes". When learning activities are driven by internal needs and self-motivation rather than by the external impetus of teachers or compulsory courses, a completely different learning motivation is come into being. The establishment of selfmotivation mechanism often originates from the recognition of college students' self-value realization, the sense of mission to the family and the sense of responsibility towards the society. The college department should enhance the effect of implicit education on the learning ability of college students by holding the educational activities of "telling the stories around us and set up outstanding model ".

4) To implement the management system and strengthen the learning control ability: At present, colleges and universities should build an effective incentive mechanism and strict constraint mechanism through the system construction to create an invisible tool to assist self-control and ensure the smooth progress of self-education. College students in American colleges and universities who have cheating in exams will give warning, dismiss or even not apply to the university. The record of cheating will be recorded in the personal credit file, which will affect the future life so there are seldom cheating in America. Now all kinds of rules and regulations in colleges and universities of China are strict, multiple and comprehensive, but there are loopholes in implementation process. Complete rules and regulations will be nominal if they are mere formality.
Therefore, implementing rules and regulations is one of the prerequisites for strengthening college students' selflearning. At the moment many colleges and universities have introduced the regulations about college students' management. The leaders at all levels of the colleges and universities should implement strictly, and the administrative departments of educational and academic work should also put it into practice.

5) To participate in learning and practice and improve comprehensive ability: Contemporary college students have strong self-awareness and are eager to gain recognition and respect from others. Campus cultural activities and social practice provide college students with a platform to display their specialty and exercise themselves. College students will have a strong sense of belonging and identity with college and university students' organizations through participation in various practical activities. Therefore, schools should encourage college students to participate in campus cultural activities and school affairs and create conditions and opportunities for university students to study independently. The University of Missouri-Kansas in the United States provides a number of practice platforms oncampus for college students, including campus management and infrastructure assessment management. The university library has administrators and counselors for college students; college students' dormitories have administrators; there are more than 100 university student staff in each department of the Student Affairs Center. The school employs a large number of college students to participate in campus management so that college students participate in the construction and development of the school personally and they have the right to conduct a comprehensive assessment of the teacher's class teaching level and even the school's supporting hardware facilities. College student organizations have played an important role in condensing campus culture, promoting college students' learning and self-education ability.

\section{CONCLUSION}

All in all, learning ability is very important. With an effective learning method, university students can remember knowledge they learn for a long time and learn more deeply. In addition, such a kind of ability can make students adjust to new environment quickly and efficiently. Autonomous learning ability must be cultivated, but students in universities must apply scientific methods. Teachers can't be excluded from the process. They should assistant students to make more achievement.

\section{REFERENCES}

[1] Lamon, M.(2003). Constructivist Approach (A). In J. W. Guthrie (Ed.) .Encyclopedia of Education (2nd ed.) (M).New York: Macmillan Reference USA, 2003, 1463.

[2] G. Hao. (2015). Study Theories and Approaches of University Students. Beijing: Renmin Press(116) 
[3] J. Zhao. Y. Song(2012) Comparative Study of Moral Education Approaches to University Students between U.S. and China. Research of Adult Education. (9) :185-186.

[4] The author.(2011). Student Affairs Management of University in U.S. Renmin University Press.

[5] Y. Liu. (2015). Academic Guidance of University Students in U.S. --taking M. University as an example. Heilongiiang higher education research. (7):55.

[6] The effect of education (EB/OL) . (2016- 05- 10) .http://www. zybang.com/question/967a35e2902d48af8779ca45—c8bf3ff3.html. 